\title{
Resternotomy Following Sternal Bone Cement Implantation: A Great Challenge for Cardiac Surgeons
}

\author{
Aliasghar Moeinipour¹, Alireza Sepehri Shamloo², Alireza Abdollahi Moghadam1, \\ Mohammad Sobhan Sheikh Andalibi' ${ }^{2}$ Ahmad Reza Zarifian' ${ }^{2}$, Hamid Hoseinikhah ${ }^{1 *}$ \\ ${ }^{1}$ Atherosclerosis Prevention Research Center, Imam Reza Hospital, Mashhad University of Medical Sciences, \\ Mashhad, Iran \\ ${ }^{2}$ Student Research Committee, Mashhad University of Medical Sciences, Mashhad, Iran \\ Email: moinipoora1@mums.ac.ir, sephria871@gmail.com, AndalibiMS891@mums.ac.ir, \\ ZarifianAR891@mums.ac.ir, AbdollahiAR@mums.ac.ir, "HoseinikhahH@mums.ac.ir
}

Received 13 October 2015; accepted 15 November 2015; published 18 November 2015

Copyright (C) 2015 by authors and Scientific Research Publishing Inc.

This work is licensed under the Creative Commons Attribution International License (CC BY).

http://creativecommons.org/licenses/by/4.0/

c) (i) Open Access

\section{Abstract}

Background: Median sternotomy and resternotomy is the standard technique for coronary artery bypass grafting (CABG), valvular heart disease, and congenital heart disease. Despite advances in many areas of cardiac surgical procedures, there is a lack of innovation in sternal closure techniques. Several studies have examined sternal closure techniques including wiring, interlocking, plate and screw, and bone cementation. However, none of them achieved widespread acceptability. On one hand, serious post-operative complications are associated with the use of wiring and plating techniques in high-risk patients. The aim of this study is showing challenges and difficulties with resternotomy in patient with a history of previous cardiac surgery and usage of biologic bone cements. Case Report: The case was a 56-year-old woman with a history of previous sternotomy for mitral and aortic valve replacement (mechanical sj. No. 29 and mechanical sj. No. 21, respectively) using biologic bone cement (Kryptonite TM, Doctors Research Group Inc.) for her osteopenic sternum. Four years after the mitral valve replacement (MVR), she was referred to emergency department with a thrombosis at the mitral valve. She underwent emergent cardiac surgery with a very difficult resternotomy under femoral cannulation support. Conclusion: Resternotomy in patients with previous sternotomy with Kryptonite bone cements or calcium phosphate cements (CPC) is safe and can be done similar to other cardiac reoperations. It seems that reoperation in this patients does not increase the risk of bleeding, morbidity, and mortality.

${ }^{*}$ Corresponding author.

How to cite this paper: Moeinipour, A., Shamloo, A.S., Moghadam, A.A., Andalibi, M.S.S., Zarifian, A.R. and Hoseinikhah, H. (2015) Resternotomy Following Sternal Bone Cement Implantation: A Great Challenge for Cardiac Surgeons. Journal of Biosciences and Medicines, 3, 77-81. http://dx.doi.org/10.4236/jbm.2015.311010 
Keywords

\section{Kryptonite Sternal Bone Cement, Resternotomy, Cardiac Complication}

\section{Background}

Median sternotomy is a type of cardiac surgical procedures, in which a vertical inline incision is made along the sternum and the sternum itself is divided to provide access to the heart and lungs for surgical procedures including corrective surgery for congenital heart defects and coronary artery bypass grafting (CABG). Then, the sternum is closed using the sternum wires. With the advent of coronary bypass operation in 1968, median sternotomy became one of the most common surgical procedures [1] [2].

Severe complications of median sternotomy are deep wound infections. Preoperative and intraoperative risk factors for deep wound infections include diabetes, obesity, respiratory insufficiency, corticosteroids and immunosuppressive drugs, prolonged perfusion time, use of one or more internal mammary arteries as grafts, blood transfusion, and mechanical circulatory assistance. The chief postoperative risk factor is reoperation, which usually causes bleeding [3].

A major causative factor in development of sternal wound infections is bone instability after sternotomy. Osteoporosis, especially in advanced ages, may be a significant risk factor for dehiscence and Mediastinitis, which predisposes the patient to non-union, mal-union, deep sternal wound infections, and subsequent mediastinitis. Reinforced sternal-closure system and rigid plate fixation are effective and safe sternal fixation methods and are used in elderly patients undergoing cardiac surgery [4] [5].

Early debridement and coverage of the remained defects with flaps are the two main principles in the management of post-sternotomy infected wounds, especially in situations where rapid wound healing and recovery are extremely important. Proper selection of the reconstruction method significantly reduces postoperative morbidity and mortality [6] [7].

The ideal sternal closure should ensure stability, reduce the rate of post-operative complications, decrease hospitalization period, and be cost-effective. Despite that cerclage wire fixation remains the standard technique for closure of sternotomies, rigid sternal fixation can be used as well in sternal reconstructions for traumatic fractures, nonunion, and pectus deformities. Rigid sternal fixation can be used safely and effectively as a prophylaxis against mediastinitis in high-risk patients [8]-[10].

Postoperative osteoconductive biologic bone cement (Kryptonite TM, Doctors Research Group Inc.) has been used as an adjunct to conventional sternal closure in patients who underwent sternotomy. This new technique may also lead to improvement in patient recovery and decrease postoperative complications [11]-[14].

Bone cements have no intrinsic adhesive properties, but they rely instead on close mechanical interlock between the irregular bone surface and the prosthesis. Used in conjunction with wires, it improves stability; however, they still rely on the use of wires and do not add any significant benefit to post-operative healing. Other types of commercially available bone cements such as calcium phosphate cements and Glass polyalkenoate (ionomer) cements (GPCs) are successfully used in a variety of orthopedic and dental applications [12] [15]-[17].

Calcium phosphate cements (CPCs) would increase healing and infection rates due to the release of antiinflammatory and anti-bacterial ions, respectively. These glasses will also be tailored to release other therapeutic ions. Besides, GPCs degrade over time and form a layer of hydroxyapatite, which would eliminate the complications associated with osteoporotic sternums [16].

\section{Case Report}

In this case study, we describe a 56-year-old woman with history of rheumatic heart disease who underwent median sternotomy and replacement of mitral and aortic valves (mechanical sj. No. 29 and mechanical sj. No. 21, respectively) in 2011 (4 years ago). The sternotomy was done using bone cements due to patient's severe sternal osteoporosis. The patient had been discharged from hospital without any complications and referred routinely for her follow-up.

Despite good follow up during the past 4 years, the patient presented at our cardiac surgery emergency department with dyspnea. She was initially admitted to cardiac emergency ward and a complete workup including 
trans-esophageal echocardiography (TEE) and fluoroscopy of the heart valves was performed for her.

The aortic valve fluoroscopy showed multiple clots and anterior leaflet developed thrombosis; thus, emergent reoperation was planned for her. Before we start the resternotomy procedure, femoral artery access was provided due to previous sternal bone cement and risk of devastating cardiac adhesion. Resternotomy was done under general anesthesia without cardiac rupture or any other cardiac complications. In the operation field, residual bone cements adherent to right ventricle was seen (Figure 1 and Figure 2). In spite of the seemingly difficult removal, it was simply removed without any complications (Figure 3). The clot removal and aortic valve replacement procedures were successfully completed and the patient eventually discharged from hospital, eight days later.

\section{Discussion}

Bone cements that bond to the sternum after CABG surgery, improve patient's quality of life and spirometry, reduce pain and disability, and reduce the amount of analgesics needed after surgery [18]. There are no reported side effects or adverse outcomes of Kryptonite and calcium phosphate cements, but surgeons need to consider the chest tubes below the breastplate as the sternum is closed so that they do not adhere to the glue. Up to now, the glue has been used only in stable patients, and surgeons should be cautious about using the cement in unsta-

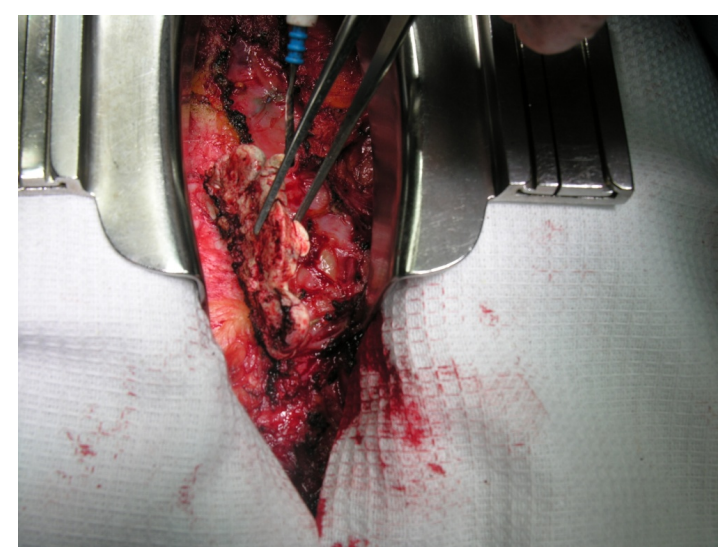

Figure 1. Resternotomy in the patient with sternal bone cement.

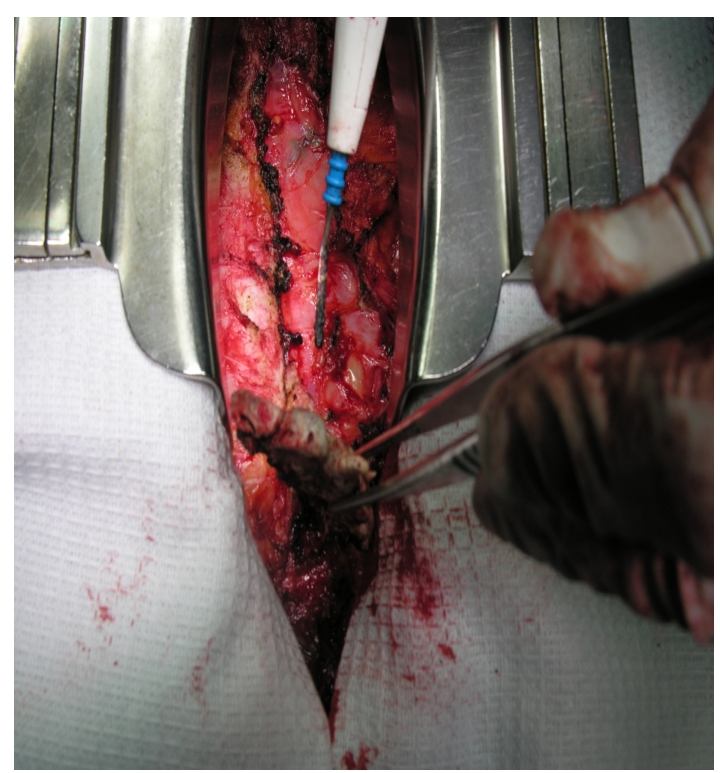

Figure 2. Bone cement removal. 


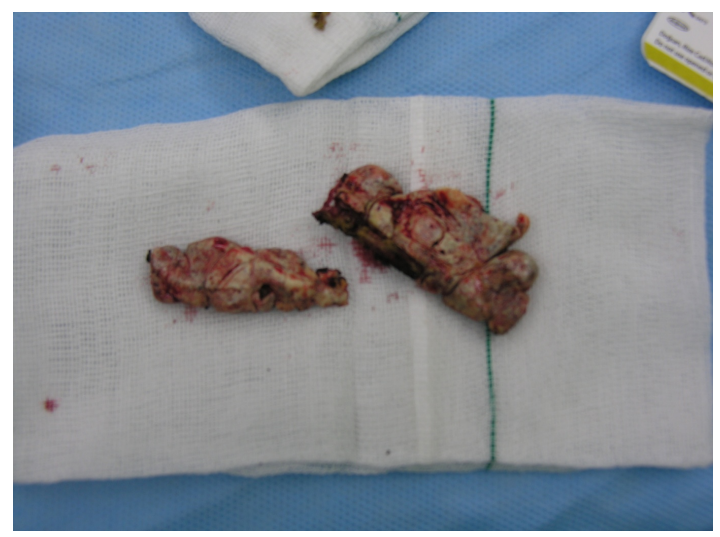

Figure 3. Removed pieces of bone cement.

ble patients or those at high risk for postoperative bleeding, since it requires more time to reenter the chest cavity in case a resternotomy is needed [18].

Graf K. et al. in their study in 2009 included 1268 patients who underwent cardiac surgery, from whom 121 patients $(9.54 \%)$ were readmitted within one year after the operation. The main causes of readmission were congestive heart failure (17.3\%), sternal dehiscence (14.9\%), rhythm and conduction disturbances (14.9\%), wound infection (11.6\%), recurrent angina pectoris (11.6\%), and pericardial effusion (10.7\%) [19].

Kryptonite cement, a polymeric material synthesized from castor oil and calcium carbonate powder, has been shown to prevent sternal displacements when used in conjunctions with wire cerclage closure [13].

\section{Conclusion}

Resternotomy in patients with use of biologic bone cement (Kryptonite TM, Doctors Research Group Inc.) is challenging and has the risk of massive bleeding. However, we found resternotomy in this patient with sternal bone cement same as other resternotomies. We recommend use of Kryptonite cements in patients with valvular or congenital heart disease who have a history of osteoporosis.

\section{Acknowledgements}

We gratefully thank Mrs. Nastaran Moeinipour and Mr. Mohammad Bizadi and Marseyeh Abdollahi for their corporation in editing this article.

\section{Conflict of Interests}

The author declares that they have no conflict of interest.

\section{References}

[1] Falor, W.H. and Traylor, R. (1982) Extended Indications for the Median Sternotomy Incision. American Surgon, 48, 582-583.

[2] Dalton, M.L. and Connally, S.R. (1993) Median Sternotomy. Surgery, Gynecology \& Obstetrics, 176, 615-624.

[3] Bryan, C.S. and Yarbrough, W.M. (2013) Preventing Deep Wound Infection after Coronary Artery Bypass Grafting: A Review. Texas Heart Institute Journal, 40, 125-139.

[4] Okutan, H., Tenekeci, C. and Kutsal, A. (2005) The Reinforced Sternal Closure System Is Reliable to Use in Elderly Patients. Journal of Cardiac Surgery, 20, 271-273. http://dx.doi.org/10.1111/j.1540-8191.2005.200432.x

[5] Song, D.H., Lohman, R.F., Renucci, J.D., Jeevanandam, V. and Raman, J. (2004) Primary Sternal Plating in High-Risk Patients Prevents Mediastinitis. European Journal of Cardio-Thoracic Surgery, 26, 367-372. http://dx.doi.org/10.1016/j.ejcts.2004.04.038

[6] Redžek, A., Mironicki, M., Gvozdenović, A., Petrović, M., Čemerlić-Ađić, N., Ilić, A. and Velicki, L. (2015) Predictors for Hospital Readmission after Cardiac Surgery. Journal of Cardiac Surgery, 30, 1-6. http://dx.doi.org/10.1111/jocs.12441 
[7] Antohi, N., Stan, V., Huian, C. and Nae, S. (2014) Poststernotomy Wound Management by Debridement and Pedicle Flaps Reconstruction. Chirurgia (Bucur), 109, 670-677.

[8] Nazerali, R.S., Hinchcliff, K. and Wong, M.S. (2014) Rigid Fixation for the Prevention and Treatment of Sternal Complications. Annals of Plastic Surgery, 72, S27-S30. http://dx.doi.org/10.1097/SAP.0000000000000155

[9] Song, D.H., Lohman, R.F., Renucci, J.D., Jeevanandam, V. and Raman, J. (2004) Primary Sternal Plating in High-Risk Patients Prevents Mediastinitis. European Journal of Cardio-Thoracic Surgery, 26, 367-372. http://dx.doi.org/10.1016/j.ejcts.2004.04.038

[10] Hashim, S., Chin, L.Y., Krishnasamy, S., Sthaneswar, P. and Raja Mokhtar, R.A. (2015) Effect of Sternal Closure with Biological Bone Adhesive on Pain Visual Analogue Score and Serum Cytokine. Journal of Cardio-Thoracic Surgery, 17, 32. http://dx.doi.org/10.1186/s13019-015-0230-0

[11] Collaud, S., Pfofe, D., Decurtins, M. and Gelpke, H. (2012) Mesh-Bone Cement Sandwich for Sternal and Sternoclavicular Joint Reconstruction. European Journal of Cardio-Thoracic Surgery, 43.

[12] Bayramoglu, Z., Durak, Y., Bayram, M., Ulusoy, O.L., Caynak, B., Sagbas, E. and Akpınar, B. (2013) Bone CementEnhanced Sternal Closure Technique in Cardiac Surgery: Effects on Sternal Union, Pain and Life Quality. Journal of Cardio-Thoracic Surgery, 7, 182. http://dx.doi.org/10.1186/1749-8090-8-182

[13] Fedak, P.W., Kieser, T.M., Maitland, A.M., Holland, M., Kasatkin, A., Leblanc, P., Kim, J.K. and King, K.M. (2011) Adhesive-Enhanced Sternal Closure to Improve Postoperative Functional Recovery: A Pilot, Randomized Controlled Trial. Annals of Thoracic Surgery, 92, 1444-1450. http://dx.doi.org/10.1016/j.athoracsur.2011.05.014

[14] Alhalawani, A.M., Curran, D.J., Pingguan-Murphy, B., Boyd, D. and Towler, M.R. (2013) A Novel Glass Polyalkenoate Cement for Fixation and Stabilisation of the Ribcage, Post Sternotomy Surgery: An Ex-Vivo Study. Journal of Functional Biomaterials, 4, 329-357. http://dx.doi.org/10.3390/jfb4040329

[15] Vaishya, R., Chauhan, M. and Vaish, A. (2013) Bone Cement. Journal of Clinical Orthopaedics and Trauma, 4, 157-163. http://dx.doi.org/10.1016/j.jcot.2013.11.005

[16] Alhalawani, A.M. and Towler, M.R. (2013) A Review of Sternal Closure Techniques. Journal of Biomaterials Applications, 28, 483-497. http://dx.doi.org/10.1177/0885328213495426

[17] Alhalawani, A.M., Rodriguez, O., Curran, D.J., Co, R., Kieran, S., Arshad, S., Keenan, T.J., Wren, A.W., Crasto, G., Peel, S.A. and Towler, M.R. (2015) A Glass Polyalkenoate Cement Carrier for Bone Morphogenetic Proteins. Journal of Materials Science: Materials in Medicine, 26, 151. http://dx.doi.org/10.1007/s10856-015-5494-3

[18] O’Riordan, M. (2010) Surgical Kryptonite: Bone Cement Improves QoL and Physical Disability in CABG Patients. Heartwire from Medscape. http://www.medscape.com/viewarticle/731256

[19] Graf, K., Sohr, D., Haverich, A., Kühn, C., Gastmeier, P. and Chaberny, I.F. (2009) Decrease of Deep Sternal Surgical Site Infection Rates after Cardiac Surgery by a Comprehensive Infection Control Program. Interactive Cardiovascular and Thoracic Surgery, 9, 282-286. http://dx.doi.org/10.1510/icvts.2009.205286 